\title{
Apo E structure determines VLDL clearance and atherosclerosis risk in mice
}

\author{
Christopher Knouff, ${ }^{1}$ Myron E. Hinsdale, ${ }^{1}$ Hafid Mezdour, ${ }^{1}$ Michael K. Altenburg, ${ }^{1}$ \\ Masahiko Watanabe, ${ }^{1}$ Steven H. Quarfordt, ${ }^{2}$ Patrick M. Sullivan, ${ }^{1}$ and Nobuyo Maeda ${ }^{1}$
}

${ }^{1}$ Department of Pathology and Laboratory Medicine, University of North Carolina-Chapel Hill, Chapel Hill,

North Carolina 27599-7525, USA

${ }^{2}$ Department of Medicine, Durham Veterans Affairs Hospital and Duke University Medical Center,

Durham, North Carolina 27705, USA

Address correspondence to: Nobuyo Maeda, Department of Pathology and Laboratory Medicine,

University of North Carolina-Chapel Hill, Chapel Hill, North Carolina 27599-7525, USA. Phone: (919) 966-6914;

Fax: (919) 966-8800; E-mail: nobuyo@med.unc.edu

Hafid Mezdour's present address is: Institute Pasteur de Lille, Laboratoire de Genetique Experimentale, 59019 Lille, France. Masahiko Watanabe's present address is: Department of Anatomy, Hokkaido University School of Medicine, 060 Sapporo, Japan.

Patrick M. Sullivan's present address is: Department of Medicine, Division of Neurology, Duke University Medical Center,

Durham, North Carolina 27705, USA.

Received for publication December 30, 1998, and accepted in revised form May 4, 1999.

\begin{abstract}
We have generated mice expressing the human apo $\mathrm{E} 4$ isoform in place of the endogenous murine apo E protein and have compared them with mice expressing the human apo E3 isoform. Plasma lipid and apolipoprotein levels in the mice expressing only the apo E4 isoform (4/4) did not differ significantly from those in mice with the apo E3 isoform (3/3) on chow and were equally elevated in response to increased lipid and cholesterol in their diet. However, on all diets tested, the $4 / 4$ mice had approximately twice the amount of cholesterol, apo E, and apo B-48 in their VLDL as did 3/3 mice. The 4/4 VLDL competed with human LDL for binding to the human LDL receptor slightly better than $3 / 3 \mathrm{VLDL}$, but the VLDL clearance rate in $4 / 4$ mice was half that in $3 / 3$ mice. On an atherogenic diet, there was a trend toward greater atherosclerotic plaque size in $4 / 4$ mice compared with $3 / 3$ mice. These data, together with our earlier observations in wild-type and human $A P O E^{*} 2$-replacement mice, demonstrate a direct and highly significant correlation between VLDL clearance rate and mean atherosclerotic plaque size. Therefore, differences solely in apo $\mathrm{E}$ protein structure are sufficient to cause alterations in VLDL residence time and atherosclerosis risk in mice.
\end{abstract}

J. Clin. Invest. 103:1579-1586 (1999).

\section{Introduction}

Apo $\mathrm{E}$ is a $34-\mathrm{kDa}$ plasma protein important for the metabolism of plasma lipoproteins (1). Like other apolipoproteins, apo E contains multiple 22-amino acid repeats that form amphipathic helices, enabling it to associate with the surface of plasma lipoproteins. Apo E also contains a stretch of basic residues (136-150) that is important for high-affinity binding to the LDL receptor and subsequent endocytosis of the associated lipoprotein particle (2). In addition, apo E mediates lipoprotein interactions with LDL receptor-related protein (LRP) (3), the VLDL receptor (4), other lipoprotein receptors (5), endothelial heparin sulfate (6), and plasma lipases $(7,8)$. The phenotype of severe hyperlipidemia and spontaneous development of atherosclerosis in mice lacking apo E clearly demonstrates the central role of apo $\mathrm{E}$ in mammalian lipid metabolism $(9,10)$.

In humans, the APOE gene is polymorphic and has 3 alleles: $A P O E^{*} 2, A P O E^{*} 3$, and $A P O E^{*} 4$. These alleles have frequencies of $7 \%, 77 \%$, and $15 \%$, respectively, in the general population (11). The $A P O E^{*} 3$ allele codes for cysteine at position 112 and for arginine at 158 . The $A P O E^{*} 2$ allele codes cysteines at both positions, whereas the $A P O E^{*} 4$ allele codes for arginines at both positions. Various population-based studies have suggested that the different $A P O E$ alleles have distinct influences on lipid metabolism in humans. Possession of at least 1 copy of the $A P O E^{*} 2$ allele has been associated with higher plasma apo E (12) and lower plasma cholesterol, LDL cholesterol, and apo B levels (11) when compared with $A P O E^{*} 3$ homozygotes. The $A P O E^{*} 2$ allele is also associated with lower risk of coronary artery disease (13), except in $5-10 \%$ of $A P O E^{*} 2$ homozygotes who develop type III hyperlipoproteinemia and premature atherosclerosis (14). On the other hand, the presence of at least $1 \mathrm{APOE}^{*} 4$ allele is associated with lower plasma apo $\mathrm{E}$ (12) and increased plasma cholesterol, LDL cholesterol, and apo B levels (11), and a greater risk of coronary artery disease (13), when compared with $A P O E^{*} 3$ homozygotes. Davignon et al. (11) estimate that the apo E polymorphism accounts for $2.8 \%$ of the variation of risk for atherosclerosis, which is a large contribution for a single locus in this complex, polygenic disease.

The availability of a well-defined model system should benefit studies of the role of the human apo E polymorphism in lipid metabolism and atherosclerosis. To develop such a model, we have used gene targeting to replace the murine Apoe gene with the 3 human APOE alleles. These mice retain the murine Apoe regulatory sequences and solely produce human apo E proteins with different 
primary structures. Previously, we reported mice homozygous for the human $A P O E^{*} 3(15)$ and $A P O E^{*} 2$ (16) alleles (referred to as $3 / 3$ and $2 / 2$ mice, respectively) in place of the coding sequences of the murine Apoe gene. The tissue apo E mRNA distribution and levels in the $3 / 3$ mice were similar to the distribution and levels of murine apo E mRNA in wild-type mice. The $3 / 3$ mice on regular mouse chow had normal plasma lipid profiles; however, when fed a high-fat diet containing cholate (HFC), the $3 / 3$ mice proved more susceptible to diet-induced lipemia and atherosclerosis than did wild-type mice. On the other hand, all the 2/2 mice exhibited features of type III hyperlipidemia, with 2.5 times the plasma total cholesterol and triglycerides of wild-type mice, in addition to spontaneous atherosclerotic lesion formation, even on a normal chow diet - regardless of age or sex.

In the present study, the plasma lipoproteins and risk of atherosclerosis in mice homozygous for the $A P O E^{*} 4$ allele (4/4 mice) and in $3 / 3$ and $2 / 2$ mice are compared. We show that the $4 / 4$ mice have increased steady-state levels of non-HDL lipoproteins due mainly to reduced VLDL plasma clearance. A direct and highly significant correlation between the VLDL plasma residence time and the extent of atherosclerosis is seen in mice expressing the different apo E isoforms. These results show that the differences in apo $\mathrm{E}$ protein structure in the common human isoforms alone are sufficient to cause differing VLDL clearance rates and atherosclerosis risk in mice.

\section{Methods}

Generation of mice expressing human apo E4. Replacement of the mouse Apoe gene with the human APOE*4 allele was achieved in mouse embryonic stem cells as described previously (15), except that the targeting construct contained exons 2-4 of $A P O E^{*} 4$ instead of $A P O E^{*} 3$. Germ-line transmission of the modified gene was achieved as described (15). All the mice used in this study were F2-generation hybrids between $129 \times$ C57BL/ 6 from 8 to 20 weeks of age unless otherwise stated. Genotypes were determined using Southern blotting (15) or an allele-specific PCR approach as described (17). Animals were maintained on normal chow containing $4.5 \%$ fat and $0.022 \%$ cholesterol (Prolab Isopro Rat/Mouse/Hamster 3000; catalog no. 5P76; Agway Inc., Syracuse, New York, USA), or were fed an atherogenic diet (HFC) containing $15.8 \%$ fat, $1.25 \%$ cholesterol, and $0.5 \%$ sodium cholate (TD 88051; Harlan Teklad, Madison, Wisconsin, USA) or a high-fat Western-style diet (HFW) containing $21 \%$ fat and $0.2 \%$ cholesterol (TD 88137; Harlan Teklad). The animals were handled under protocols approved by the Institutional Animal Care and Use Committees of the University of North Carolina-Chapel Hill.

Plasma lipid and lipoprotein analysis. Plasma was isolated, and total cholesterol (free and esterified) and triglycerides were measured as described previously (15). HDL cholesterol was measured according to Warnick et al. (18). VLDL was isolated by ultracentrifugation at a density of $1.006 \mathrm{~g} / \mathrm{mL}$ from either $1 \mathrm{~mL}$ of plasma pooled from mice of identical apo E genotype or $200 \mu \mathrm{L}$ of plasma from individual mice. LDL was isolated after removing the VLDL fraction by spinning at a density of $1.063 \mathrm{~g} / \mathrm{mL}$. Total lipoproteins were isolated at a density of $1.21 \mathrm{~g} / \mathrm{mL}$. Lipopro-

\section{Table 1}

tein fractions were dialyzed against PBS. Plasma $(100 \mu \mathrm{L})$ pooled samples were fractionated by fast protein liquid chromatography (FPLC) using a Superose 6 HR10/30 column (Pharmacia Biotech Inc., Piscataway, New Jersey, USA). Apo E was measured using an ELISA with antibodies specific for human apo E as described (19). Apo B-100 levels were measured using an ELISA with a primary apo B-100 mAb from a hybridoma cell line kindly supplied by S. Young (Gladstone Institute, University of California-San Francisco, San Francisco, California, USA) and a secondary polyclonal apo B antibody kindly supplied by H. de Silva (University of North Carolina-Charlotte, Charlotte, North Carolina, USA). Apo B-100/apo B-48 ratios were determined by densitometry of bands of SDS-PAGE of total plasma lipoproteins followed by Coomassie brilliant blue staining. Isoelectric focusing of whole plasma was performed according to the method of Hackler et al. (20). Electron microscopy of isolated VLDL was done according to the method of Forte and Nordhausen (21). Female mice were used for these analyses unless otherwise stated.

$L D L$ receptor binding and particle internalization assay. The binding and internalization of VLDL via the human LDL receptor were assayed using a modification of the competition method of Goldstein and Brown (22) and Weisgraber et al. (23), using human LDL labeled with 1,1'-dioctadecyl-3, 3, 3', 3'tetramethylindocarbocyanine perchlorate (DilC 18 ; Molecular Probes Inc., Eugene, Oregon, USA), as described by Stephan and Yurachek (24). VLDL was isolated by ultracentrifugation from female mice of each genotype maintained on an HFC diet. Protein concentrations were determined using a colorimetric assay (Bio-Rad Laboratories Inc., Richmond, California, USA). Immortalized human fibroblast cells (kindly provided by J. Herz, University of Texas-Southwestern, Dallas Texas, USA) were grown in 24-well plates with DMEM and 10\% FBS to $90 \%$ confluence. The medium was replaced with DMEM containing $0.5 \%$ BSA at 24 hours before the experiment. Labeled human LDL $(50 \mu \mathrm{g} / \mathrm{mL})$ was added to each well, along with increasing amounts of murine VLDL, ranging from $0.5 \mu \mathrm{g} / \mathrm{mL}$ up to $100 \mu \mathrm{g} / \mathrm{mL}$. Cells were incubated at $37^{\circ} \mathrm{C}$ to determine cellular association and internalization of particles. After incubation, the media were removed, cells were washed 4 times with PBS, and fluorescence was measured with excitation and emission wavelengths of $520 \mathrm{~nm}$ and $578 \mathrm{~nm}$, respectively. Cell number was normalized between plates and between experiments by total protein concentration of representative wells. The average of 4 wells was used for each data point, and values for $K_{i}$ were determined by averaging the results of 3 experiments carried out at $37^{\circ} \mathrm{C}$.

$V L D L$ clearance assay. Clearance rate of VLDL from the circulation of $3 / 3$ and $4 / 4$ mice was determined as described previously (15), using $\left[{ }^{14} \mathrm{C}\right]$ cholesterol-labeled VLDL $(d<1.010)$ isolated from apo $\mathrm{E}$ knockout mice on normal chow or from $3 / 3$

Plasma lipid and apo E concentrations in the $3 / 3$ and $4 / 4$ mice

\begin{tabular}{|c|c|c|c|c|c|}
\hline Genotype & Diet & $\begin{array}{c}\mathrm{TC} \\
\mathrm{mg} / \mathrm{dL}\end{array}$ & $\begin{array}{c}\mathrm{TG} \\
\mathrm{mg} / \mathrm{dL}\end{array}$ & $\begin{array}{l}\mathrm{HDL}-\mathrm{C} \\
\mathrm{mg} / \mathrm{dL}\end{array}$ & $\begin{array}{l}\text { Apo E } \\
\mathrm{mg} / \mathrm{dL}\end{array}$ \\
\hline \multirow{3}{*}{$3 / 3$} & NC & $75 \pm 26(30)$ & $52 \pm 26(30)$ & $61 \pm 24(12)$ & $1.2 \pm 0.5(6)$ \\
\hline & HFC & $363 \pm 97(11)$ & $16 \pm 11(11)$ & $25 \pm 8(11)$ & $13.6 \pm 8.6(11)$ \\
\hline & HFW & $122 \pm 43(7)$ & $48 \pm 4(7)$ & $107 \pm 38(7)$ & $1.8 \pm 0.3(6)$ \\
\hline \multirow{3}{*}{$4 / 4$} & NC & $72 \pm 27(30)$ & $49 \pm 22(30)$ & $58 \pm 22(12)$ & $1.6 \pm 0.7(6)$ \\
\hline & HFC & $380 \pm 64(11)$ & $18 \pm 2(11)$ & $20 \pm 10(11)$ & $11.7 \pm 3.8(11)$ \\
\hline & HFW & $130 \pm 27(6)$ & $66 \pm 31(6)$ & $74 \pm 18(6)$ & $3.0 \pm 1.3(4)$ \\
\hline
\end{tabular}

Data are means \pm SD of fasted female mice receiving chow (NC) high-fat cholate (HFC), or high-fat western (HFW) diets. Parentheses show number of mice analyzed. No values were significantly different between genotypes on equel diets. TC, total cholesterol; TG, triglycerides; HDL-C, HDL cholesterol. 
or 4/4 mice on normal chow. The fractional catabolic rates and their variances were determined as described previously using a two-compartment model (25). Three age-matched males of each genotype were used for each experiment.

Triglyceride secretion assay. Triglyceride secretion rate was determined according to the procedure of Li et al. (26). Briefly, female mice of each genotype on normal chow were fasted for 4 hours. The $4 / 4$ mice were F2 generation, and the $3 / 3$ mice were F3 generation and were age matched between 8 and 20 weeks of age. Plasma was collected for triglyceride measurements at time 0 and at 30,60, and 120 minutes after injection of Tyloxapol (Triton WR-1339; Sigma Chemical Co., St. Louis, Missouri, USA) via tail vein at a dose of $0.7 \mathrm{mg} / \mathrm{g}$ body weight. At 5 hours, the animals were exsanguinated and total liver weight was measured. Rates of triglyceride secretion were calculated, normalized for liver weight, and expressed as milligrams of triglyceride per hour, assuming that the plasma volume of mice is $4.5 \%$ of body weight.

Evaluation of atherosclerotic lesions. Female mice were fed an atherogenic diet (HFC) for 3 months before sacrifice. Atherosclerotic plaque sizes in aortic root sections were determined as described previously (27).

Statistical analysis. The significance of differences between means was calculated by using either a two-tailed unpaired Student $t$ test or one-way ANOVA followed by Tukey-Kramer Honestly Significant Difference test (JMP software; SAS Inc., Cary, North Carolina, USA).

\section{Results}

Production of functional apo E4 in mice with buman APOE*4. Mice in which the murine Apoe gene was replaced with the human $A P O E^{*} 4$ allele were generated using procedures described previously (15). Targeted modification of the locus was confirmed at the DNA level by Southern blotting and by the presence of $A P O E^{*} 4$-specific fragments in PCR followed by HhaI digest of the genomic DNA isolated from mouse tails (data not shown). Separation of plasma proteins via isoelectric focusing, which distinguishes the 3 human apo $\mathrm{E}$ isoforms by their charge differences due to differing arginine content, revealed that the apo E4 protein in the mice homozygous for the modified gene (4/4) is indistinguishable from human apo E4 standards (Figure 1a). Thus, the apo E4 protein expressed in 4/4 mice was the same charge and size as the apo $\mathrm{E} 4$ protein isolated from human plasma.

Expression of functional apo E4 protein was determined by assessing the capacity of VLDL from the 4/4 mice to bind to the human LDL receptor using an in vitro competition assay. VLDL was isolated from $4 / 4,3 / 3$, or $2 / 2$ mice maintained on an HFC diet and was used to compete with human LDL labeled with a lipophilic fluorescent dye $\left(\mathrm{DilC}_{18}\right)$ for binding to, and internalization by, the LDL receptor on human fibroblasts (24). The results shown in Figure $1 \mathrm{~b}$ demonstrate that the apo E4 in VLDL from the 4/4 mice and apo E3 in VLDL from the 3/3 mice both compete well with human LDL for binding and uptake by the human LDL receptor. Ki determined from 3 repeated experiments, each consisting of quadruple measurements, were $3.6 \pm 0.6 \mathrm{mg}$ for $4 / 4 \mathrm{VLDL}$ and $5.7 \pm 1.12 \mathrm{mg}$ for $3 / 3$ $\operatorname{VLDL}(\mathrm{P}=0.05$ by one-way ANOVA). Therefore, the $4 / 4$ VLDL has the ability to compete with human LDL for binding to the human LDL receptor better than the $3 / 3$ VLDL. Apo E2 in the VLDL from the 2/2 mice competes poorly with human LDL for binding to the human LDL receptor $(K i=69 \pm 8 \mathrm{mg} ; \mathrm{P}<0.01$ vs. $3 / 3)$. These data demonstrate that the ability of VLDL to compete with labeled LDL for cellular binding and internalization increases in the 3 lines of mice in the order $4 / 4>3 / 3>2 / 2$.

Increased non-HDL lipoproteins in 4/4 mice. In humans, $A P O E^{*} 4$ is associated with increased plasma and LDL cholesterol (11). We therefore examined plasma lipid and apolipoprotein levels in the 4/4 mice and compared them with those in the $3 / 3$ mice. On all diets tested, total plasma cholesterol, triglycerides, HDL-cholesterol, and apo E protein amount did not differ significantly between the 2 genotypes. Table 1 presents the values for female mice. Chow-fed male mice had higher plasma lipid levels than females did, but there were no genotypedependent differences (data not shown). These data indi-

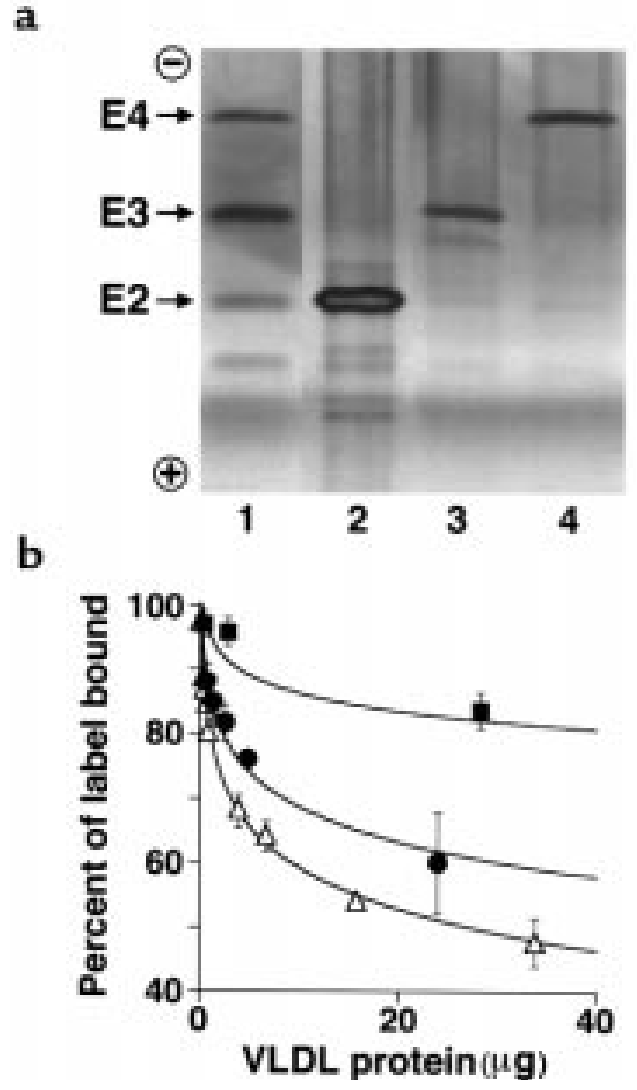

Figure 1

(a) Mice with the 3 human apo $E$ isoforms. Delipidated plasma samples from 2/2 (lane 2), 3/3 (lane 3), and 4/4 (lane 4) mice were separated by isoelectric focusing, and the apo $\mathrm{E}$ proteins were viewed by silver staining after immunofixation with an anti-human apo E antibody. The positions of the human apo $E$ isoforms - E2, E3, and E4 - are indicated. Lane 1 shows apo E2, apo E3, and apo E4 from mixed human plasma as controls. (b) Competition assay of human LDL receptor binding and internalization of VLDL from $2 / 2,3 / 3$, and $4 / 4$ mice. VLDL was isolated from 2/2 (filled squares), $3 / 3$ (filled circles), and 4/4 (open triangles) mice maintained on an HFC diet by ultracentrifugation of plasma pooled from at least 6 animals, and it was used to compete with DilC $\mathrm{C}_{18^{-}}$ labeled human LDL for binding to human fibroblasts. Values are the mean - SD of 4 wells from a representative experiment carried out at $37^{\circ} \mathrm{C}$. VLDL amounts are expressed as micrograms of total protein. The apo $E$ content of the isolated VLDL was approximately $17 \pm 3 \%, 7 \pm 3 \%$, and $4 \pm 1 \%$ of total protein for $2 / 2,3 / 3$, and $4 / 4 \mathrm{VLDL}$, respectively ( $P$ $<0.001$ by one-way ANOVA). 

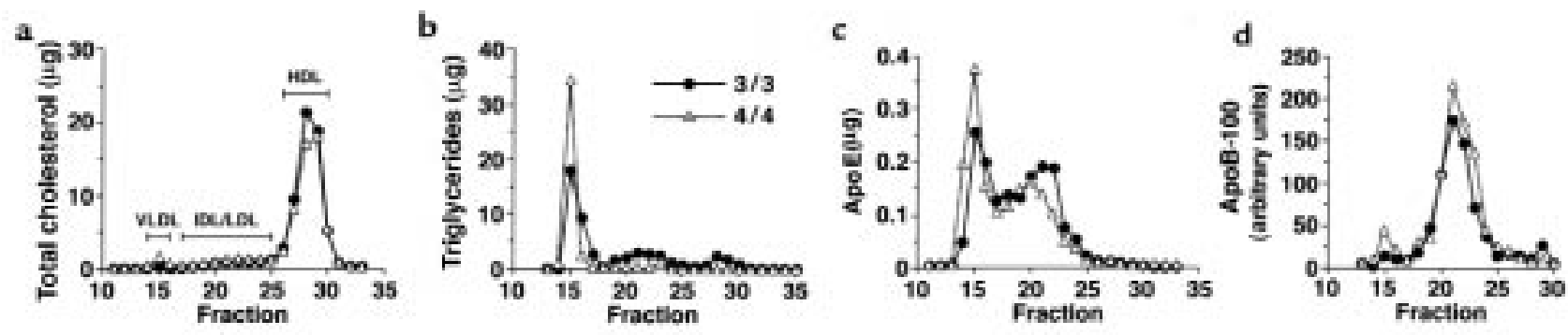

e
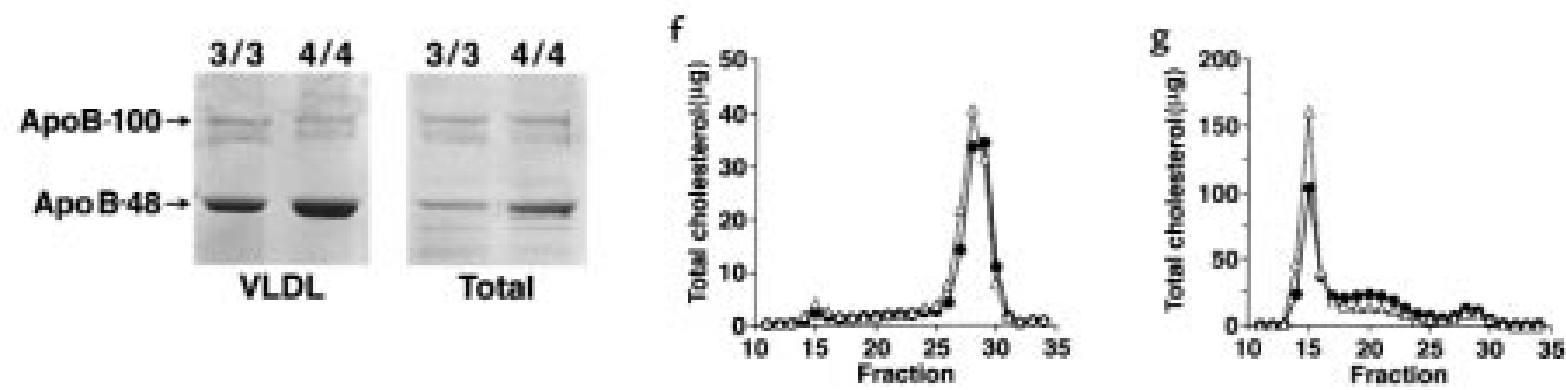

Figure 2

Distribution of plasma lipoproteins, apo E, and apo B-100 in mice fed normal chow (a-e), HFW (f), and HFC (g). Pooled plasma (100 $\mu \mathrm{L})$ from 6 age-matched female mice was fractionated by gel filtration chromatography on a Superose 6B column, and 0.5-mL fractions were collected. Fractions containing VLDL, IDL/LDL, and HDL are shown. (a) Total cholesterol was measured in micrograms per fraction. (b) Triglycerides were measured in micrograms per fraction. (c) Apo $\mathrm{E}$ (micrograms per fraction) was measured using an ELISA with antibodies specific for human apo E. (d) Apo B-100 was measured using an ELISA with antibodies specific for mouse apo B-100 and is expressed as arbitrary units per fraction. (e) Apo B100 and apo B-48 of isolated VLDL ( $80 \mu \mathrm{L}$ plasma equivalent) or total lipoproteins ( $25 \mu \mathrm{L}$ plasma equivalent) from $3 / 3$ and $4 / 4$ mice were viewed by Coomassie blue staining after SDS-PAGE on 3-20\% gradient gel. (f) Total cholesterol was measured in micrograms per fraction in at least 5 female mice maintained on an HFW diet for 2 months. (g) Total cholesterol was measured in micrograms per fraction in at least 5 female mice maintained on an HFC diet for 2 months.

cate that the $4 / 4$ and $3 / 3$ mice maintain normal plasma lipid levels on chow diet and that both lines are equally susceptible to HFC diet-induced hyperlipidemia.

Although overall plasma lipid levels are similar between the $3 / 3$ and $4 / 4$ mice on normal chow, the distribution of lipid in various lipoprotein fractions was different. FPLC analysis of plasma from $4 / 4$ mice showed that the amounts of cholesterol, triglyceride, and apo E were slightly greater in the VLDL fractions (fractions 14-16), whereas they were slightly less in the HDL fractions (fractions 26-30), compared with 3/3 mice (Figure 2, a-c). The increase in VLDL cholesterol in 4/4 mice compared with $3 / 3$ mice was also seen on an HFW diet (Figure $2 f$ ) and an HFC diet (Figure 2g). On the other hand, the cholesterol in other particles (IDL, LDL, and HDL) was slightly reduced in 4/4 mice compared with 3/3 mice on an HFC diet (Figure $2 \mathrm{~g}$ ). Ultracentrifugation of plasma confirmed these results, with a statistically significant $(P<0.05)$ higher level of VLDL cholesterol in 4/4 mice maintained on an HFW or HFC diet compared with $3 / 3$ mice on similar diets (Figure 3). Ultracentrifugation also showed that on normal chow, there was a significantly greater cholesterol/triglyceride ratio in $4 / 4 \mathrm{VLDL}$ compared with $3 / 3$ $\operatorname{VLDL}(0.87 \pm 0.45$ in $4 / 4$ vs. $0.33 \pm 0.5$ in $3 / 3 ; P<0.01)$. The cholesterol levels in the LDL fraction on all diets did not differ significantly between the 2 groups of mice.

There was no marked difference in relative apolipoprotein composition in lipoprotein fractions isolated by ultracentrifugation from $4 / 4$ and $3 / 3$ mice on normal chow by SDS-PAGE analysis (data not shown). However, amounts of apo E and apo B-48 (by SDS-PAGE; Figure $2 \mathrm{e}$ ) in the VLDL fraction of 4/4 mice were approximately twice those of the $3 / 3$ mice. Plasma total apo B-100 levels determined by ELISA were not significantly different between the $4 / 4$ or $3 / 3$ mice $(7.4 \pm 1.6$ in the $3 / 3$ mice and $9.1 \pm 4.4$ in the $4 / 4$ mice; arbitrary units, $n=6$ ). The high apo B-48 in the VLDL of 4/4 mice results in differences in the apo B-100/apo B-48 ratios between these animals (0.7 in $4 / 4$ mice compared with 1.2 in $3 / 3$ mice on normal chow). Taken together, these results show that on normal chow, 4/4 mice have a 2-fold greater amount of apo B48-containing VLDL particles compared with $3 / 3$ mice.

Increased diameter of $4 / 4$ VLDL particles. To determine whether the increase in lipids and apolipoproteins in the 4/4 VLDL is due to differences in the size of the particles, we examined the diameter of the VLDL particles by electron microscopy. VLDL was isolated by ultracentrifugation from plasma pooled from 4 female mice of each genotype maintained on normal chow. There was a significant increase in diameter of VLDL from the $4 / 4$ mice $(43 \pm 13 \mathrm{~nm}$; mean $\pm \mathrm{SD}, n=416)$ compared with the $3 / 3$ mice $(41 \pm 14 \mathrm{~nm} ; n=270, P<0.05$ vs. $4 / 4)$ and $2 / 2$ mice $(36 \pm 11 \mathrm{~nm} ; n=358, P<0.01$ vs. $3 / 3)$. The fraction of VLDL larger than $45 \mathrm{~nm}$ in diameter in the $4 / 4$ mice was $39 \%$ compared with $31 \%$ and $17 \%$ in the $3 / 3$ and $2 / 2$ mice, respectively. Approximately $9 \%$ of particles from $4 / 4$ and $3 / 3$, but only $4 \%$ of the particles from $2 / 2$, mice had a diameter larger than $60 \mathrm{~nm}$. This analy- 
sis suggests that the VLDL particles of $4 / 4$ mice have a $15 \%$ greater volume than $3 / 3 \mathrm{VLDL}$ and, when taken together with previous results, suggests that both the size and number of VLDL particles are greater in the $4 / 4$ animals. In contrast, the $2 / 2 \mathrm{VLDL}$ particles have $25 \%$ less volume compared with $3 / 3$ VLDL particles. The markedly greater triglycerides and cholesterol in the VLDL fraction of the $2 / 2$ mice compared with the $3 / 3$ mice is therefore due to the former having a greater number of VLDL particles. This suggests that there are different mechanisms accounting for the observed high levels of VLDL cholesterol in the $2 / 2$ and $4 / 4$ mice compared with the $3 / 3$ mice.

Delayed VLDL clearance in 4/4 mice. To understand the basis for differences between steady-state VLDL levels in the plasma of $4 / 4$ mice and $3 / 3$ mice, the clearance rate of $\left[{ }^{14} \mathrm{C}\right]$ cholesterol-labeled VLDL introduced into these mice was analyzed. The clearance of injected apo E-deficient VLDL was slower in 4/4 mice compared with $3 / 3$ mice fed a normal chow diet (Figure $4 \mathrm{a}$ ), with a fractional catabolic rate of $0.6 \pm 0.06$ pools $/ \mathrm{h}$ in the $4 / 4$ mice compared with $1.2 \pm 0.07$ pools $/ h$ in the $3 / 3$ mice $(n=5$, $P<0.001)$. Even though the clearance rate was less in the $4 / 4$ mice, the levels of labeled VLDL were reduced to baseline by 4 hours, whereas those in the $3 / 3$ mice were reduced to baseline by 2 hours.

The differences in clearance of apo E-deficient VLDL could be due to differences in the ability of plasma apo $\mathrm{E}$ proteins to be transferred from endogenous VLDL to the injected apo E-deficient VLDL particles. We therefore repeated the experiments using labeled VLDL from donors of the same genotype as the recipients. A similarly low fractional catabolic rate $(0.8 \pm 0.08$ pools $/ \mathrm{h})$ was observed in $4 / 4$ mice compared with $3 / 3$ mice $(1.5 \pm 0.3$ pools/h; $n=5, P<0.05$ ) when VLDL obtained from $4 / 4$ or $3 / 3$ donor mice was injected into homologous recipient mice (Figure 4b). Additionally, the initial clearance rate (less than 2 minutes) was significantly faster for homologous donor VLDL than for apo E-deficient donor VLDL for both genotypes $(P<0.05)$.

In a preliminary experiment, we also labeled lipoproteins in $3 / 3$ or $4 / 4$ mice and then isolated and injected the labeled VLDL into 2 mice of the opposite genotype, i.e., $3 / 3$ VLDL into $4 / 4$ mice and 4/4 VLDL into $3 / 3$ mice. The clearance was again slower in the $4 / 4$ mice than in $3 / 3$ mice, and the clearance rate was similar to the homologous VLDL (data not shown). These results show that 4/4 mice have a significantly impaired ability to clear VLDL particles from their plasma relative to $3 / 3$ mice and that the genotype of the recipient mice, not that of the donor VLDL, determines the clearance rate.

Steady-state levels of VLDL may also be influenced by its secretion. Therefore, we investigated the secretion rate of triglycerides in all lines of mice, using Triton WR-1339 to block lipolysis and uptake of VLDL. There was no difference in the triglyceride secretion rate between the $4 / 4$ mice $(3.20 \pm 0.47 \mathrm{mg} / \mathrm{h} / \mathrm{g}$ liver; $n=7)$ and $3 / 3$ mice $(3.22$ $\pm 0.33 \mathrm{mg} / \mathrm{h} / \mathrm{g} ; n=9)$. These data suggest that the increase in steady-state levels of VLDL in the 4/4 mice results mainly from the reduction of plasma VLDL clearance and not by increased VLDL secretion.
Morphometric evaluation of aortic lesions. The greater nonHDL lipoprotein levels in the 4/4 mice compared with the $3 / 3$ mice suggest that $4 / 4$ mice may also be more susceptible to atherosclerosis. We therefore fed female $3 / 3$ and 4/4 mice an atherogenic diet (HFC) for 3 months to assess atherosclerotic lesion development in the proximal aorta near the aortic root. The mean lesion size in the $4 / 4$ mice $\left(14.7 \pm 8.9 \times 10^{4} \mu \mathrm{m}^{2} ; n=17\right)$ was twice as large as in $3 / 3$ mice $\left(7.7 \pm 5.0 \times 10^{4} \mu \mathrm{m}^{2} ; n=12, P=0.11\right)$. The large variation in plaque size developing in the F2 animals precluded this difference from reaching statistical significance $(P=0.11)$, but there already is a trend of increased lesion size in the $4 / 4$ mice. This increase in lesion size in 4/4 mice compared with $3 / 3$ mice correlates with the increased steady-state VLDL cholesterol and the decreased VLDL fractional catabolism in 4/4 mice compared with the $3 / 3$ control mice.

The availability in mice of 4 allelic forms of apo $\mathrm{E}$ with varied structure enables us to examine how these alleles correlate with atherogenesis. The present data on the $4 / 4$ and $3 / 3$ mice were combined with previously reported data on wild-type, $2 / 2$, and $3 / 3$ mice and are summarized in Figure 5. There is a clear hierarchy in the order of $2 / 2$ $>4 / 4>3 / 3>$ wild-type in both plasma residence time of labeled VLDL (inverse of the fractional catabolic rate) and in the size of atherosclerotic plaques. Furthermore, the correlation between mean lesion size observed in each group of mice with mean VLDL residence time was high and significant $\left(r^{2}=0.981, P<0.01\right)$. These results demonstrate the importance of apo $\mathrm{E}$ as a primary determinant of the plasma residence time of atherogenic lipoproteins and the effect of VLDL clearance rate on the extent of atherosclerotic lesions.

\section{Discussion}

In this study, we have compared the in vivo effects of the human apo E4 isoform with the effects of the human apo E3 and apo E2 isoforms on both lipoprotein metabolism and atherogenesis in mice. The mice compared are genetically equivalent, except at the coding regions of their Apoe gene. They have the normal murine regulatory regions intact and exclusively express 1 of the 3 common human apo E isoforms in a physiologically regulated manner. We find that steady-state plasma lipid levels in both the $4 / 4$ and $3 / 3$ mice are significantly lower than the levels in $2 / 2$ mice, although they are not significantly different from each other on normal chow. However, there are subtle but notable differences in lipoprotein distribution between the $4 / 4$ and $3 / 3$ mice. The $4 / 4$ mice have about twice the level of cholesterol, apo E, and apo B-48 in the VLDL fraction compared with $3 / 3$ mice. The $4 / 4$ VLDL particles have a $15 \%$ greater mean volume than the $3 / 3$ VLDL particles, which in turn have a $25 \%$ greater volume than the $2 / 2$ VLDL particles. We find by direct measurement a 2fold reduction in the VLDL clearance rate in the $4 / 4$ mice compared with the $3 / 3$ mice. This reduced clearance appears to be the main determinant of the increase in the steady-state levels of VLDL, as the VLDL secretion rates in the 2 groups of mice were not different.

The apo E4 isoform expressed in the mice we have generated is indistinguishable from that in humans at the DNA level and protein level. Furthermore, the apo E4 in 
Figure 3

VLDL cholesterol in $3 / 3$ and $4 / 4$ mice on 3 different diets. VLDL from plasma of 6 individual female mice maintained on normal chow (a), HFW diet (b), or atherogenic diet (HFC) (c) was isolated by ultracentrifugation. Amounts are expressed in milligrams of cholesterol per deciliter of plasma $\pm \operatorname{SD}$ ( $n=6$ for all groups).
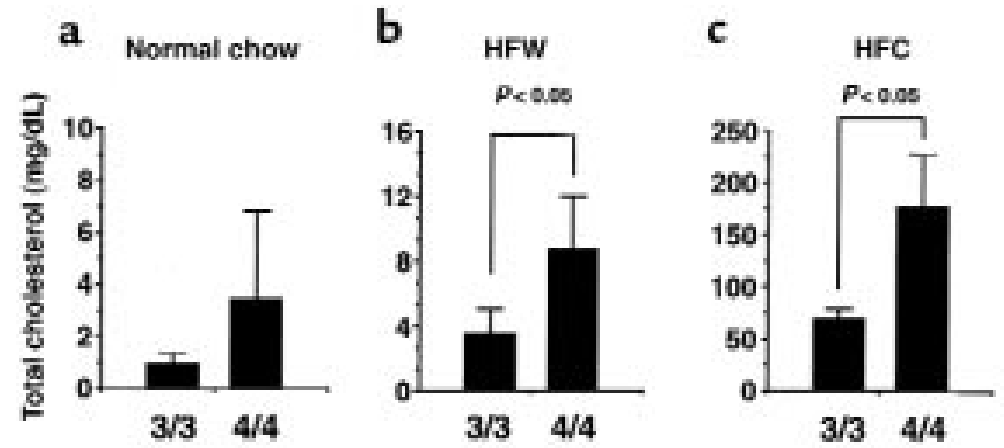

the 4/4 mice is completely functional, as assessed by the demonstrated ability of VLDL from these mice to compete with human LDL for binding to the human LDL receptor. Therefore, the observed effects of apo E4 on lipid metabolism in mice are unlikely to be due to any inadvertent modifications of the APOE gene or its products introduced during the generation of the mice. The 4/4 VLDL competed with human LDL for binding to the human LDL receptor slightly better $(150 \%)$ than VLDL isolated from $3 / 3$ mice. The $2 / 2$ VLDL competed with human LDL for binding to the human LDL receptor significantly worse $(<10 \%)$ than $3 / 3$ VLDL. The hierarchy of LDL receptor-binding affinity of the 3 apo $\mathrm{E}$ isoforms expressed in the mice agrees with the results by Bohnet et al. (28), who used labeled VLDL isolated from human subjects with the different apo E isoforms and showed that apo E4-containing particles had the highest affinity (122\%) for the LDL receptor, followed by apo E3-containing particles (100\%) and apo E2-containing particles (37\%). Similarly, Weisgraber et al. (23) showed that purified apo E2 reconstituted with dimyristoylphosphatidylcholine disks has only $1 \%$ the affinity of apo E3 for the LDL receptor.

Although, as in humans with $A P O E^{*} 4$ and $A P O E^{*} 3$, the 4/4 mice have more non-HDL particles and slightly less HDL compared with the $3 / 3$ mice, there are some differences between the observations in humans and mice. Most notably, in the 4/4 mice the majority of non-HDL cholesterol is in the VLDL fraction, not the LDL fraction as in humans. Furthermore, substantially more apo B-48 is present in the $4 / 4$ mice compared with the $3 / 3$ mice, and this increase in apo B-48 was not accompanied by any change in the apo B-100 levels. These differences are not surprising given that in mice, but not in humans, about
$70 \%$ of the apo B mRNA is edited in the liver (29). This results in production of apo B-48-containing VLDL by the liver in mice, whereas human liver produces only apo B-100-containing VLDL. Apo B-48-containing lipoprotein particles are processed differently than apo B100-containing particles; the former requires apo $\mathrm{E}$ for receptor binding and has a much shorter plasma half-life than the latter (30). Consequently, mice have a greater dependence on apo E proteins for lipoprotein clearance than humans. The hepatic output of apo B-48 likely contributes to the severe type III hyperlipidemia in the $2 / 2$ mice and the preferential accumulation of apo B-48-containing particles over apo B-100-containing particles in 4/4 mice, both being exaggerated phenotypes compared with humans. Additionally, we note that species differences in lipid metabolism between mice with human apo E isoforms and humans may also result from the fact that the human protein in mice has to interact with many murine proteins, and these interactions may not necessarily be identical to those occurring in humans.

A long-standing hypothesis advanced to explain the metabolic effects of different apo E isoforms is that differences in apo E isoform LDL receptor-binding affinity result in differences in hepatic LDL receptor levels (11). According to this hypothesis, the lower LDL receptor affinity of apo E2 decreases cellular cholesterol influx, and the resulting smaller intracellular sterol pools lead to upregulation of the LDL receptor. The effects of apo E4 are less clear, but it has been hypothesized that the LDL receptor is downregulated in individuals with an $A P O E^{*} 4$ as a result of an enhanced uptake of apo E-containing VLDL remnants $(31,32)$. However, we find that remnant clearance in our $4 / 4$ mice is slower
Figure 4

The plasma clearance of VLDL in $3 / 3$ and $4 / 4$ mice. Three male mice maintained on normal chow of each group (filled circles, 3/3; open triangles, 4/4) were injected with radiolabeled remnant particles from apo E-deficient donor mice (a) or from donor mice of the same genotype (b), and the fraction of radioactivity remaining in plasma was measured for 2 hours. Each data point shows mean - SD. The SD of some data is smaller than the data points. a

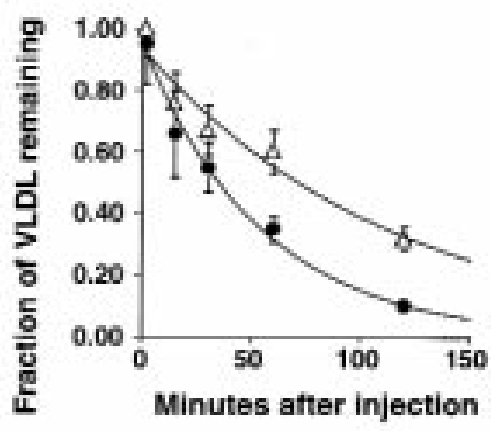

b

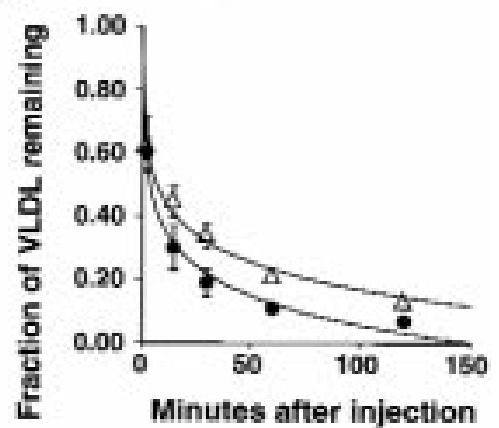


than in the $3 / 3$ mice. Furthermore, although the receptor hypothesis predicts that reduced LDL receptor expression causes an accumulation of apo B-100-containing particles, we found no increase in apo B-100 LDL in the 4/4 mice. Rather, there was an increase in apo B48 particles in the VLDL range in the $4 / 4$ mice compared with the $3 / 3$ mice. Our results agree more with an alternative hypothesis proposed by Bergeron and Havel (33) that the prolonged residence times of VLDL remnants in persons carrying the $A P O E^{*} 4$ allele raise the concentration of LDL by increasing the amount of VLDL converted to LDL. Normolipidemic male $4 / 3$ subjects studied by these investigators exhibited increased postprandial apo B-48 and lipid levels compared with $3 / 3$ subjects (33). An increased conversion of VLDL to smaller remnants and a relative decrease in direct removal of VLDL in E4 homozygotes compared with $\mathrm{E} 3$ subjects have also been demonstrated by Demant et al. (34).

The delayed clearance of VLDL remnants in the $4 / 4$ mice compared with the $3 / 3$ mice appears to be due to intrinsic differences in the recipient animals themselves rather than their VLDL particles, as judged by our preliminary results of introducing $4 / 4$ particles into $3 / 3$ mice and $3 / 3$ particles into $4 / 4$ mice. It is therefore tempting to speculate that the greater amount of VLDL in $4 / 4$ mice compared with $3 / 3$ mice, and particularly the increase of particles containing apo B-48 but not apo B-100, may be related to the differential interaction of VLDL particles with the hepatic microenvironment. For example, LRP is important in clearing apo B-48-containing particles but less so in clearing apo B-100-containing particles (35). Various in vitro or tissue culture-based experiments have suggested equal LRP-binding affinity as well as cholesterol delivery to cells by lipoprotein particles with apo E4 and apo E3 $(3,36)$. The implication of these observations for in vivo VLDL remnant uptake is unclear, and there is evidence that remnant clearance through LRP requires hepatic apo E expression (37). It may be that there are isoform-specific differences in intracellular distribution of apo $\mathrm{E}$ in hepatocytes that result in differences in LRP processing. Alternatively, there may be isoform-specific differences in hepatocyte apo E secretion, resulting in differences in secretion-capture of VLDL remnants. Cullen et al. (38) have recently shown that the amount of apo E released from the cell surface by suramin and heparinase treatments is greater with macrophages expressing apo E4 than with those expressing apo E3. Isoform-specific differences in hepatocyte distribution of apo E, and their influence on receptor-mediated uptake of remnant particles, merit further investigation.

The present experiments impinge directly on the influence of apo E genotype on the development of atherosclerotic lesions after feeding an atherogenic diet. Our data (presented in Figure 5) show a highly significant relationship $(P<0.01)$ between the sizes of atherosclerotic plaques in the aortic sinus of wild-type, $2 / 2,3 / 3$, and $4 / 4$ mice and plasma residence time of exogenously introduced VLDL (inverse of the fractional catabolic rate). Because the only systematic genetic difference among these animals is at their Apoe locus, our experiments enable us to establish unequivocally that the structure of the apo E protein is the primary determi-

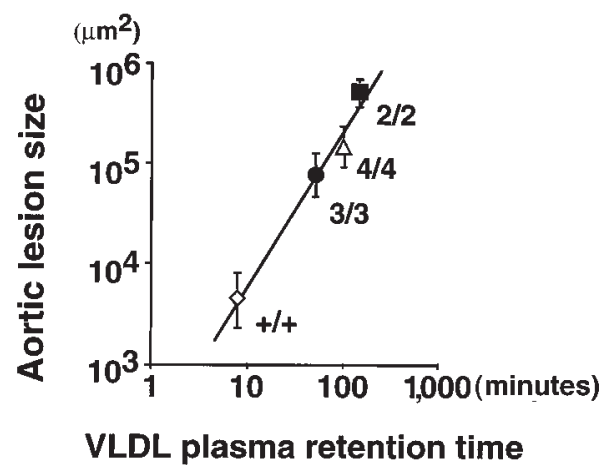

Figure 5

Correlation between atherosclerotic lesion size and circulation time of VLDL particles. Atherosclerotic lesion area from at least 6 female mice maintained on an HFC diet for 3 months was determined. The log of the mean lesion size was plotted against $\beta$-VLDL retention time (inverse of the fractional catabolic rate; Figure 4 and refs. 15, 16), as determined from at least 3 mice injected with apo E-deficient labeled VLDL. The symbols are as follows: wild-type (open diamond), 2/2 (filled square), 3/3 (filled circle), and 4/4 (open triangle).

nant of atherosclerosis risk and of VLDL residence time in these mice. We recognize that the exact relationships between apo $\mathrm{E}$ isoform and atherosclerosis risk observed in mice may not be directly transferable to humans. Thus, the majority of human individuals homozygous for $A P O E^{*} 2$ show lower incidents of cardiovascular diseases than those with other APOE genotypes (13). The $2 / 2$ mice are similar to the fraction of human-3 $A P O E^{*} 2$ homozygotes who display type III hyperlipidemia and develop premature atherosclerosis. On the other hand, our observation that the $4 / 4$ mice tend to develop larger plaques than the $3 / 3$ mice on an atherogenic diet mirror the findings in humans that possession of an $A P O E^{*} 4$ allele is associated with higher risk for coronary disease (13). Finally, the direct and highly significant correlation between the plasma residence time of remnant particles and the extent of atherosclerotic lesions seen in the mice is clear experimental support for the hypothesis that any prolongation of the half-life of non-HDL lipoprotein increases the likelihood that it will be modified into atherogenic forms (reviewed in ref. 39).

In conclusion, our study demonstrates that mice having targeted replacements of the intrinsic murine Apoe gene with the 3 human $A P O E$ alleles recapitulate many of the phenotypic effects seen in humans with these same isoforms. Furthermore, these mice provide direct experimental proof that the degree of atherosclerosis is correlated with the residency time of atherogenic lipoproteins in the plasma and show that changes only in the apo E protein structure are sufficient to determine both the residency time of atherogenic lipoproteins in plasma and the extent of lesions after feeding on an atherogenic diet.

\section{Acknowledgments}

We thank K. Kluckman, S. Kim, B. Oswald, D. Lee, and A. Stanton for technical assistance; A. Steinmetz for apo E typing using isoelectric focusing of mouse plasma; and P. Herron, A. Attie, and O. Smithies for review of the manuscript. We also thank J. 
Griffith and A. Makhov at the University of North Carolina EM core facility (National Institutes of Health grants CA-16086) for electron microscopy. This work was supported by National Institutes of Health grants HL-42630 (to N. Maeda) and RR00111 (to M. Hisdale).

1. Mahley, R.W. 1988. Apolipoprotein E: cholesterol transport protein with an expanding role in cell biology. Science. 240:622-630.

2. Weisgraber, K.H. 1994. Apolipoprotein E: structure-function relationships. Adv. Protein Chem. 45:249-302.

3. Kowal, R.C., et al. 1990. Opposing effects of apolipoproteins E and C on lipoprotein binding to low density lipoprotein receptor-related protein. $J$. Biol. Chem. 265:10771-10779.

4. Takahashi, S., Kawarabayasi, Y., Nakai, T., Sakai, J., and Yamamoto, T. 1992. Rabbit very low density lipoprotein receptor: a low density lipoprotein receptor-like protein with distinct ligand specificity. Proc. Natl. Acad. Sci. USA. 89:9252-9256.

5. Yamamoto, T., and Bujo, H. 1996. Close encounters with apolipoprotein E receptors. Curr. Opin. Lipidol. 7:298-302.

6. Weisgraber, K.H., et al. 1986. Human apolipoprotein E. Determination of the heparin binding sites of apolipoprotein E3. J. Biol. Chem. 261:2068-2076.

7. Saxena, U., Ferguson, E., and Bisgaier, C.L. 1993. Apolipoprotein E modulates low density lipoprotein retention by lipoprotein lipase anchored to subendothelial matrix. J. Biol. Chem. 268:14812-14819.

8. Thuren, T., Weisgraber, K.H., Sisson, P., and Waite, M. 1992. Role of apolipoprotein $\mathrm{E}$ in hepatic lipase catalyzed hydrolysis of phospholipid in high-density lipoproteins. Biochemistry. 31:2332-2338.

9. Zhang, S.H., Reddick, R.L., Piedrahita, J.A., and Maeda, N. 1992. Spontaneous hypercholesteremia and arterial lesions in mice lacking apolipoprotein E. Science. 258:468-471.

10. Plump, A.S., et al. 1992. Severe hypercholesteremia and atherosclerosis in apolipoprotein E-deficient mice created by homologous recombination in ES cells. Cell. 71:343-353.

11. Davignon, J., Gregg, R.E., and Sing, C.F. 1988. Apolipoprotein E polymorphism and atherosclerosis. Arteriosclerosis. 8:1-21.

12. Boerwinkle, E., and Utermann, G. 1988. Simultaneous effects of the apolipoprotein E polymorphism on apolipoprotein E, apolipoprotein B, and cholesterol metabolism. Am. J. Hum. Genet. 42:104-112.

13. Wilson, P.W.F., Schaefer, E.J., Larson, M.G., and Ordovas, J. M. 1996. Apolipoprotein E alleles and risk of coronary disease. Arterioscler. Thromb. Vasc. Biol. 16:1250-1255.

14. Brewer, H.B., Jr., Zech, L.A., Gregg, R.E., Schwartz, D., and Schaefer, E.J. 1983. NIH conference. Type III hyperlipidemia: diagnosis, molecular defects, pathology, and treatment. Ann. Intern. Med. 98:623-640.

15. Sullivan, P.M., et al. 1997. Targeted replacement of the mouse apolipoprotein E gene with the common human APOE3 allele enhances diet-induced hypercholesteremia and atherosclerosis. J. Biol. Chem. 272:17972-17980.

16. Sullivan, P.M., Mezdour, H., Quarfordt, S.H., and Maeda, N. 1998. Type III hyperlipidemia and spontaneous atherosclerosis in mice resulting from gene replacement of mouse Apoe with human APOE*2. J. Clin. Invest. 102:130-135.

17. Hixson, J.E., and Vernier, D.T. 1990. Restriction isotyping of human apolipoprotein E by gene amplification and cleavage with HhaI.J. Lipid Res. 31:545-548.

18. Warnick, G.R., Benderson J., and Albers, J.J., 1982. Dextran sulfate $\mathrm{Mg}^{2+}$ precipitation procedure for quantification of high-density-lipoprotein cholesterol. Clin. Chem. 28:1379-1388.

19. Leroy A., Vu-dac, N., Koffigan, M., Clavey, V., and Fruchart, J. C. 1988.
Characterization of a monoclonal antibody that binds to apolipoprotein $\mathrm{E}$ and to lipoprotein of human plasma containing apoE. Applications to ELISA quantification of plasma apoE. J. Immunoassay. 9:309-334

20. Hackler, R., et al. 1994. Rapid determination of apolipoprotein E phenotypes from whole plasma by automated isoelectric focusing using PhastSystem and immunofixation. J. Lipid Res. 35:153-158.

21. Forte, T.M., and Nordhausen, R.W. 1986. Electron microscopy of negatively stained lipoproteins. Methods Enzymol. 128:442-472.

22. Goldstein, J.L., and Brown, M.S. 1974. Binding and degradation of low density lipoprotein by cultured human fibroblasts. Comparison of cells from a normal subject and from a patient with homozygous familial hypercholesteremia. J. Biol. Chem. 249:5153-5162.

23. Weisgraber, K.H., Innerarity, T.L., and Mahley, R.W. 1982. Abnormal lipoprotein receptor-binding activity of the human $E$ apoprotein due to a cysteinearginine interchange at a single site. J. Biol. Chem. 257:2518-2521.

24. Stephan, Z.F., and Yurachek, A.C. 1993. Rapid fluorometric assay of LDL receptor activity by DiI-labeled LDL. J. Lipid Res. 34:325-330.

25. Quarfordt, S.H., et al. 1995. In vivo cholesterol kinetics in apolipoprotein E-deficient and control mice. J. Lipid Res. 36:1227-1235.

26. Li, X., Catalina, F., Grundy, S.M., and Patel, S. 1996. Method to measure apolipoprotein B-48 and B-100 secretion rates in an individual mouse: evidence for a very rapid turnover of VLDL and preferential removal of B-48relative to B-100-containing lipoproteins. J. Lipid Res. 37:210-220.

27. Paigen, B., Morrow, A., Holmes P.A., Mitchell, D., and Williams, R.A. 1987. Quantitative assessment of atherosclerotic lesions in mice. Atherosclerosis. 68:231-240.

28. Bohnet, K., Pillot, T., Visvikis, S., Sabolovic, N., and Siest, G. 1996. Apolipoprotein (apo) E genotype and apoE concentration determine binding of normal very low density lipoproteins to HepG2 cell surface receptors. J. Lipid Res. 37:1316-1324.

29. Chan, L., Chang, B.H., Nahamuta, M., Li, W.H., and Smith L.C. 1997. Apobec1 and apolipoprotein B mRNA editing. Biochim. Biophys. Acta. 1345:11-26.

30. Hussain, M.M., et al. 1996. Chylomicron assembly and catabolism: role of apolipoproteins and receptors. Biochim. Biophys. Acta. 1300:151-170.

31. Gregg, R.E., et al. 1986. Abnormal in vivo metabolism of apolipoprotein E4 in humans. J. Clin. Invest. 78:815-821.

32. Weintraub, M.S., Eisenberg, S., and Breslow, J.L. 1987. Dietary fat clearance in normal subjects is regulated by genetic variation in apolipoprotein E. $J$. Clin. Invest. 80:1571-1577.

33. Bergeron, N., and Havel, R.J. 1996. Prolonged postprandial responses of lipids and apolipoproteins in triglyceride-rich lipoproteins of individuals expressing an apolipoprotein $\varepsilon 4$ allele. J. Clin. Invest. 97:65-72.

34. Demant, T., Bedford, D., Packard, C.J., and Shepherd, J. 1991. Influence of apolipoprotein E polymorphism on apolipoprotein B-100 metabolism in normolipidemic subjects. J. Clin. Invest. 88:490-501.

35. Veniant, M.M., et al. 1998. Lipoprotein clearance mechanisms in LDL receptor-deficient "apoB-48-only" and "apoB-100-only" mice. J. Clin. Invest. 102:1559-1568

36. Ji, Z.S., Pitas, R.E., and Mahley, R.W. 1998. Differential cellular accumulation/retention of apolipoprotein E mediated by cell surface heparin sulfate proteoglycans. Apolipoproteins E3 and E2 greater than E4. J. Biol. Chem. 273:13452-13460.

37. Linton, M.F., Hasty A.H., Babaev, V.R., and Fazio S. 1998. Hepatic apoE expression is required for remnant lipoprotein clearance in the absence of the low density lipoprotein receptor. J. Clin. Invest. 101:1726-1736.

38. Cullen, P., et al. 1998. Phenotype-dependent differences in apolipoprotein E metabolism and in cholesterol homeostasis in human monocyte-derived macrophages. J. Clin. Invest. 101:1670-1677.

39. Steinberg, D. 1983. Lipoproteins and atherosclerosis. A look back and a look ahead [review]. Arteriosclerosis. 3:283-301. 